\title{
Mittheilung über einen Fall von Haematoma vulvae im Verlaufe der Schwangerschaft.
}

Von

Ehrendorfer.

Zur Aetiologie der an dem weiblichen Genitale vorkommenden Hämatome möge folgender Fall, wegen Seltenheit des ursächlichen Momentes, einen Beitrag liefern. Am 10. Juli 1888 wurde Frau J. W., 32 Jahre alt, in die Innsbrucker Frauenklinik aufgenommen. Seit dem 20. Lebensjahre ist die Frau regelmässig menstruirt, hat vier Mal natürlich geboren und giebt an, dass seit fünf Monaten die Regeln wieder ausgeblieben seien und sie seit etwa vier Wochen Kindsbewegungen spüre. Sie erzählt ferner auf eingehende Fragen, dass sie vor zehn Tagen, als ihr Mann im angeheiterten Zustande einen ziemlich stürmischen Coitus ausgeführt, plötzlich einen äusserst heftigen Schmerz in der rechten grossen Schamlippe verspürt habe, so dass der Coitus, bevor es noch zur Fjaculatio gekommen war, sofort unterbrochen werden musste. In kurzer Zeit soll sich nun, unter anhaltenden Schmerzen, in der Gegend der rechten grossen Schamlippe eine etwa hühnereigrosse Geschwulst gebildet haben und nach und nach bis über Mannsfaustgrösse angewachsen sein. Der den nächsten Tag gerufene Arzt verordnete Bettruhe und Bleiwasserumschläge, welche einige Tage fortgesetzt wurden. Die Geschwulst soll sich seither verkleinert und die Schmerzen sollen etwas abgenommen haben, doch sucht die Kranke wegen rascherer Wiederherstellung Hülfe im Spitale.

Die Kranke ist mittelgross, blass, mässig genährt. Temperatur normal. Puls voll und ruhig. Brüste colostrumhaltig. Ueber der linken Lungenspitze gedämpfter Schall, am Herzen nichts Regelwidriges. Das Abdomen kugelig vorgewölbt durch den schwangeren Uterus, dessen Grund etwa 2 Querfinger über den Nabel reicht. In den rechtsseitigen Leistenkanal kann der kleine Finger eindringen und drängen sich während des Hustens Darmschlingen Archiv f. Gynäkologie. Bd. XXXIV. Hft. 1. 
aus demselben hervor. An dem äusseren Genitale sieht man die linken Schamlippen etwas blutreicher, aber sonst regelmässig. Rechts dagegen ist die grosse Schamlippe durch einen Tumor stark ausgedehnt und entfaltet, so dass die Geschwulst von dem oberen Rande der Symphyse bis zum Anus reicht, eine Länge (über die Kuppe gemessen) von $13 \mathrm{~cm}$ und eine Breite von über $10 \mathrm{~cm}$ besitzt. Der Tumor ist von bläulichschwarzer Farbe und derb-elastischer Consistenz. Fluctuation ist an zwei Stellen wahrnehmbar, die von der daselbst sehr dünn ausgespannten Haut bedeckt sind. Die Temperatur über der Geschwulst ist nicht erhöht, in der Umgebung keine Reaction, die Druckempfindlichkeit jedoch ist eine beträchtliche. An dem inneren Antheile des Tumor verläuft die dunkel gefärbte, etwas ödematöse, aber nicht entfaltete, rechte kleine Schamlippe. $\mathrm{Zu}$ bemerken ist noch, dass der Tumor zum Theile über den Scheideneingang hinaus, gegen die Vagina $\mathrm{zu}$, sich erstreckt.

Da die Kranke infolge des Tumor am Gehen gehindert ist, immer noch über Schmerzen klagt, und die Geschwulst überdies in den letzten Tagen nur wenig an Grösse abgenommen hat, so wird nach entsprechender Reinigung in der Längsrichtung der rechten grossen Schamlippe ein mehrere Centimeter langer Schnitt durch die buchtig vorgewölbte verdünnte Haut geführt, worauf bei leisem Drucke ein etwa hühnereigrosser Klumpen von schwarzrothem geronnenen Blute herausfällt. Nach vollständiger Entfernung des Coagulum und Ausspïlung der von blutig unterlaufenen Wänden umgebenen Höhle blutete es am Grunde aus dem morschen Gewebe an einer Stelle sehr lebhaft, und dürfte dieses Gefäss - da eine Verletzung mit dem Messer während der Incision nicht anzunehmen war - die Ursache des Hämatoms gewesen sein.

Die Wundhöhle wurde mit Jodoformpulver eingestäubt und mit Jodoformgazestreifen ausgefüllt. Ausspülung der Vagina, antiseptischer Verband, T-Binde. Nach der ohne Narkose ausgeführten Operation hörten alsbald die Schmerzen auf. Der Verlauf vollständig reactionslos. Der Verband wurde täglich erneuert, die Tamponade der Wundhöhle durch einige Tage wiederholt. Der Harn mittels Katheters entleert. Die Schwangerschaft nahm ungestört ibren weiteren Verlauf und wurde die Kranke nach zehn Tagen (auf eigenen Wunseh) mit einer kleinen granulirenden Wunde in bestem Wohlsein entlassen.

Bekanntlich ist das Zustandekommen eines Haematoma vulvae 
im Verlaufe des Geburtsactes keine Seltenheit. Seltener sind die Beispiele von Hämatomen ausserhalb des Puerperium, die zumeist durch rohe Gewalteinwirkung entstehen, und noch seltener dürfte als ursächliches Moment dafür die Cohabitation allein gelten, welche stürmisch wie in dem oben beschriebenen Falle ausgeführt, die Veranlassung zur Bildung eines Haematoma vulvae abgegeben hat. Den bestimmten Angaben unserer Kranken zufolge ist die Blutgeschwulst durch den Beischlaf zu Stande gekommen, ähnlich wie in dem Falle von Lawson Tait), in welchem über ein Haematoma vulvae, entstanden in der ersten Ehenacht, berichtet wird.

Es dürfte in unserem Falle die Schwangerschaftshyperämie die Entstehung eines solchen Blutergusses begünstigt haben, freilich kann man dann fragen, warum unter ähnlichen Umständen solche Hämatome an Schwangeren nicht häufiger zur Beobachtung gelangen. Varices waren bei unserer Kranken nirgends nachzuweisen, auch war durch Anamnese keine Anlage zu Blutungen überhaupt zu ergründen. Was die Behandlung solcher bereits mehrere Tage bestehenden Tumoren betrifft, so können wir nur sagen, dass, wenn die Grösse derselben die Kranken im Gehen hindert, oder die Schmerzen beträchtlich sind, die Eröffnung und antiseptische Behandlung am raschesten zur Heilung führt. Schliesslich wollen wir als erwähnenswerth bemerken, dass in unserem Falle trotz tagelang andauernder, oft sehr heftiger wehenartiger Schmerzen die fünfmonatliche Schwangerschaft ungestört ihren Fortgang nahm.

1) Diseases of women, II. edit. Birmingham 1886. 